Bull. Chem. Soc. Ethiop. 2014, 28(2), 195-204.

Printed in Ethiopia

ISSN 1011-3924

DOI: http://dx.doi.org/10.4314/bcse.v28i2.4

(c) 2014 Chemical Society of Ethiopia

\title{
EXTRACTION AND DETERMINATION OF ORGANOSULFUR COMPOUNDS IN WATER SAMPLES BY USING HOMOGENEOUS LIQUID-LIQUID MICRO- EXTRACTION VIA FLOTATION ASSISTANCE-GAS CHROMATOGRAPHY- FLAME IONIZATION DETECTION
}

\author{
Faezeh Khalilian and Mohammad Rezaee* \\ Department of Chemistry, College of Basic Science, Yadegar - e-Imam Khomeini (RAH) \\ Branch, Islamic Azad University, Tehran, Iran
}

(Received September 24, 2013; revised May 4, 2014)

\begin{abstract}
A new method was developed for the preconcentration and determination of organosulfur compounds (OSCs) in water samples using homogeneous liquid-liquid microextraction via flotation assistance (HLLME-FA) and gas chromatography (GC) with flame ionization detection (FID). Toluene at microliter volume level and acetone were used as an extraction and a homogeneous solvent, respectively. In this research, a special extraction cell was designed to facilitate collection of the low-density solvent extraction. No centrifugation was required in this procedure. Using air flotation, extraction solvent was collected at the conical part of the designed cell. The effects of the different variables on the efficiency of the extraction such as kind and the volume of extraction and homogeneous solvents, ionic strength and extraction time were studied and optimized. Under the optimum conditions, linearity of the method were in the range from 0.25 to $200 \mu \mathrm{g} \mathrm{L}^{-1}$ with limit of detections (LODs) $(\mathrm{S} / \mathrm{N}=3)$ were in the range from 0.05 to $0.4 \mu \mathrm{g} \mathrm{L}{ }^{-1}$. HLLME-FA is a fast, simple and efficient method for the determination of organic sulfur compounds in aquatic samples.
\end{abstract}

KEY WORDS: Homogeneous liquid-liquid microextraction, Flotation assistance, Organosulfur compounds, Gas chromatography, Water samples

\section{INTRODUCTION}

Organosulfur compounds (OSCs) may occur in different aquatic environment as a consequence of industrial processes such as biogas production, sewage treatment, production of dye stuffs and detergents, or natural reduction processes in the presence of high amounts of organic matter and sulfate [1-4]. Also, some OSCs are generated as minor by-products of industrial processes, such as the manufacture of plastics and tires. Volatile OSCs have also been identified as the predominant odorants from bioindustry emissions [5]. Because of their very low odor threshold and extremely unpleasant odor, they contribute to pollution even when very small amounts are emitted [6, 7]. The International Labor Organization of the United Nations reports that some sulfur compounds can cause health problems, including damage to the human respiratory system, even at low concentrations, and that exposure to high levels of OSCs can be extremely harmful, causing unconsciousness and death $[3,4,6]$. According to the above considerations, determination of OSCs in aqueous environmental samples is necessary and provides useful information about the source of input and quality of water. The determination of OSCs in aqueous environmental samples is usually carried out by methods including gas chromatography (GC) [8, 9], gas chromatography-mass spectrometry (GC-MS) [10, 11] and liquid chromatography [12].

Since the sulfur compounds are found at trace levels in the environment and due to the complexity of environmental matrices, a preconcentration step must be included in the

*Corresponding author. E-mail: r_r_mohammad@yahoo.com 
analytical procedure to detect low concentrations of these compounds. Liquid-liquid extraction [13], solid phase microextraction [14, 15], purge and trap [16], headspace sorptive extraction [17] and dispersive liquid-liquid microextraction (DLLME) [8] have been used as sample preparation methods for these compounds. Liquid-liquid extraction is time consuming or requires large amounts of toxic solvents. Solid-phase microextraction and headspace sorptive extraction are time consuming.

The main disadvantage of DLLME is that the extraction solvent is generally limited to solvents of density higher than water in order to be sedimented by centrifugation. These solvents are typically chlorinated solvents such as chlorobenzene, chloroform and carbon tetrachloride, all of which are potentially toxic to human and environment. In addition, the use of high density solvents as extractant limits wider applicability of DLLME. This is caused by the more limited choices as the number of low-density solvents is more than high-density ones. Typically, most DLLME method has a centrifugation step, which is the extra time-consuming step in the extraction. In recent years, this limitation has been recognized and there have been several reports of the application of low density solvents in solvent microextraction methods [18-28].

Typically, most DLLME and HLLE methods have a centrifugation step, which is the extra time-consuming step in the extraction. Very recently, solvent-terminated DLLME was developed by $\mathrm{Li}$ and co-workers [29] as an alternative approach, which avoided centrifugation, thereby simplifying the operation and speeding up the extraction procedure. Recent innovation to LPME includes dispersive liquid-liquid microextraction, which is based on the solidification of floating organic droplet (DLLME-SFO) [30]. This method combines the advantages of DLLME and LPME-SFO. In DLLME-SFO, a low-density and less toxic solvent was used to overcome the disadvantages of DLLME. However, in order to solidify the extraction solvent, one imposes rather stringent restrictions on the choice of the DLLME-SFO extraction solvent. For example, the extraction solvent often needs a compound with a long carbon chain such as dodecanol or hexadecane. These low-polarity solvents cannot extract some polar compounds. Moreover, with DLLME-SFO time is required for the liquid extraction solvent drop to become solid drop. Farajzadeh et al. [18] used capillary effect to collect extraction solvent by glass capillary tube. However, the floated volume needs to have enough amounts; otherwise, the capillary tube prone to collect water not to extract solvent. Furthermore, the volume of floated phase collected by capillary effect is limited.

Homogeneous liquid-liquid microextraction via flotation assistance (HLLME-FA) method was developed for the determination of polycyclic aromatic hydrocarbons (PAHs) in soil samples [31]. The objective of this study was to investigate the applicability of HLLME-FA for the preconcentration and determination of OSCs in aqueous samples prior to gas chromatography-flame ionization detection (GC-FID). In this procedure, a mixture of extraction solvent and homogeneous solvent is injected into an aqueous sample to form a homogeneous solution in the initial state and then form an emulsion consisting of fine droplets of the extraction solvent, homogeneous solvent and water. In this method, a special extraction cell was designed to facilitate collection of the low-density solvent extraction. No centrifugation was required in this procedure. By using air flotation, the organic solvent was collected at the conical part of the designed cell. The most effective variables on the HLLME-FA method could be considered as the type and volume of extraction solvent, ionic strength, the type and volume of homogeneous solvent and time of extraction. The results indicated that HLLME-FA is an efficient extraction procedure for determination of OSCs in aqueous samples. 


\section{EXPERIMENTAL}

\section{Chemicals and reagents}

The organosulfur compounds with high purity were obtained from Acros (Dutch, Belgium), Fluka (Buchs, Switzerland), Merck (Darmstadt, Germany), and Sigma-Aldrich (Missouri, USA) companies. A stock standard solution of each OSCs $\left(1000 \mathrm{mg} \mathrm{L}^{-1}\right)$ was prepared in methanol and stored in darkness at $-10{ }^{\circ} \mathrm{C}$. A fresh $10 \mathrm{mg} \mathrm{L}^{-1}$ standard solution containing the OSCs was prepared in methanol every week and stored at $4{ }^{\circ} \mathrm{C}$. The working standard solutions were prepared in doubly distilled water, stored at $4{ }^{\circ} \mathrm{C}$ in fridge, and brought to ambient temperature prior to use. The names and abbreviations of selected OSCs are summarized in Table 1. n-Hexane, n-heptane, toluene, 1-octanol, methanol, acetone, acetonitrile and sodium chloride were obtained from Merck (Darmstadt, Germany). Youngling ultra pure water purification system (Aqua $\mathrm{Max}^{\mathrm{TM}}$-ultra, Korea) was used for purification of water.

Table 1. Name and abbreviations of selected OSCs

\begin{tabular}{|l|c|c|c|}
\hline Compound & Formula & Abbreviation & B.p. $\left({ }^{\circ} \mathrm{C}\right)$ \\
\hline Methyl phenyl sulfide & $\mathrm{C}_{7} \mathrm{H}_{8} \mathrm{~S}$ & MPS & $188(\mathrm{Bp})$ \\
\hline 4-Methylthiophenol & $\mathrm{C}_{7} \mathrm{H}_{8} \mathrm{~S}$ & 4MTP & $195(\mathrm{Bp})$ \\
\hline 2-Naphthalenethiol & $\mathrm{C}_{10} \mathrm{H}_{8} \mathrm{~S}$ & 2NT & $286(\mathrm{Bp})$ \\
\hline Diphenyl sulfide & $\mathrm{C}_{12} \mathrm{H}_{10} \mathrm{~S}$ & DPS & $\mathrm{NA}^{\mathrm{a}}$ \\
\hline Benzyl phenyl sulfide & $\mathrm{C}_{13} \mathrm{H}_{12} \mathrm{~S}$ & BPS & $197(\mathrm{Bp})$ \\
\hline Thiaanthrene & $\mathrm{C}_{12} \mathrm{H}_{8} \mathrm{~S}_{2}$ & TH & $366(\mathrm{Bp})$ \\
\hline
\end{tabular}

${ }^{a}$ Not available.

\section{Instrumentation}

Separation and quantification of OSCs were carried out using an Agilent 7890 gas chromatograph, equipped with a FID detector and a DB-5 fused-silica capillary column $(30 \mathrm{~m} \times$ $0.32 \mathrm{~mm}$ i.d. $\times 0.25 \mu \mathrm{m}$ film thickness). Injection was performed at splitless mode, and helium gas with high purity was used as a carrier gas at the constant flow rate of $1.5 \mathrm{~mL} \mathrm{~min}^{-1}$. The injector and detector temperatures were 260 and $270{ }^{\circ} \mathrm{C}$, respectively. The column temperature program was as follows: $50{ }^{\circ} \mathrm{C}$ for $1 \mathrm{~min}$, increased to $100{ }^{\circ} \mathrm{C}$ at $15^{\circ} \mathrm{C} \mathrm{min}{ }^{-1}$, and then held for $1 \mathrm{~min}$. Finally, the temperature increased to $270{ }^{\circ} \mathrm{C}$ at $10{ }^{\circ} \mathrm{C} \min ^{-1}$ and then was held at $270{ }^{\circ} \mathrm{C}$ for $2 \mathrm{~min}$. The analytical signal was taken as the peak area of the organic sulfur compounds.

\section{HLLME-FA procedure}

Figure 1 shows the schematic procedure of the proposed method. A mixture of $0.5 \mathrm{~mL}$ acetone (homogeneous solvent) and $50 \mu \mathrm{L}$ toluene (extraction solvent) were added to the homedesigned microextraction cell (length $=40 \mathrm{~cm}$; diameter $=1.5 \mathrm{~cm}$ ) (Figure 1-1). A volume of 22 $\mathrm{mL}$ of the saline aqueous sample solution was injected into the microextraction cell by syringe, rapidly (Figure 1-2). In this step, in the initial state of injection, a homogeneous solution was formed and then with the continuation of injection an emulsion consisting of fine droplets of the extraction solvent were formed (Figure 1-3). After about $5 \mathrm{~min}$, by using air flotation, the organic solvent was collected on the top of the solution (Figure 1-4). After separation of the two phases, a few volumes of distilled water were added into the glass tube on the side of the cell (length $=43 \mathrm{~cm}$; diameter $=0.5 \mathrm{~cm}$ ) (Figure 1-5). The floated organic solvent was raised into the conical part of the cell (length $=1.5 \mathrm{~cm}$; diameter $=0.5 \mathrm{~cm}$ ). Using a microsyringe, two microliters of the collected organic solvent were injected into the GC-FID instrument. 


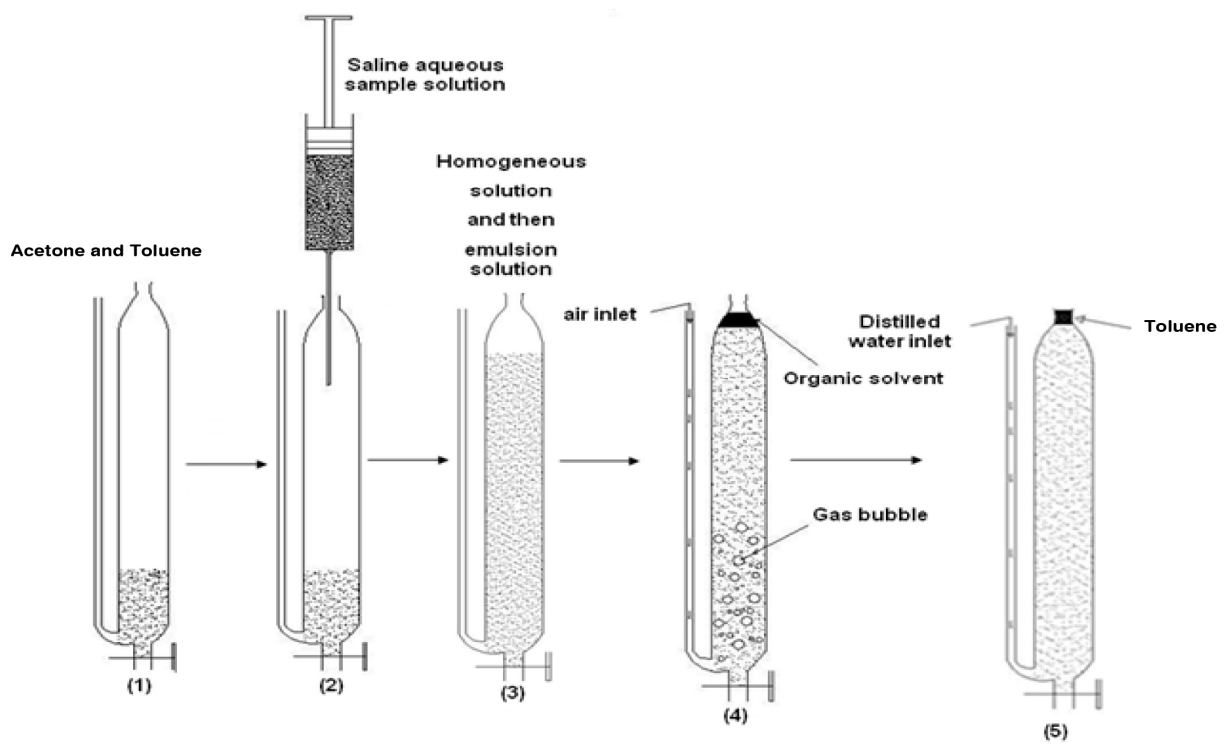

Figure 1. Schematic HLLME-FA procedure (Figure 1-1) a mixture of $0.5 \mathrm{~mL}$ acetone containing $50.0 \mu \mathrm{L}$ toluene was added to the home-designed microextraction cell, (Figure 1-2) $22.0 \mathrm{~mL}$ of the saline aqueous solution was added into the microextraction cell, (Figure 1-3) a homogeneous solution was formed in the cell, (Figure 1-4) using air flotation, organic solvent was moved to the top of the solution, (Figure 1-5) a small volume of distilled water was added into the glass tube on the side of the cell.

\section{RESULTS AND DISCUSSION}

In the present research, the HLLME-FA method combined with GC-FID was applied for the extraction and determination of OSCs in the aquatic samples. In order to obtain a high recovery and preconcentration factor, the effect of different parameters such as the type and volume of homogeneous and extraction solvents, salt addition and extraction time were examined and optimized.

\section{Selection of extraction solvent}

The selection of extraction solvent is a critical factor in HLLME-FA method. The extraction solvent must be immiscible with water, lower density than water and have high extraction capability for analytes. In our work, 1-octanol, n-hexane, n-heptane and toluene were performed as extraction solvents to analyze the effect of the solvent on extraction efficiency. It is necessary to add an excess amount of solvent to recover an equal volume of different extraction solvents in the upper layer for comparison. The final volume of the floated solvents was kept at $6.0 \mu \mathrm{L}$. The results are provided in Figure 2. As shown in Figure 2, toluene possessed the highest extraction recovery as compared with other extraction solvents. It seems that analytes have benzene group in their structure which may have facilitated interaction with benzene group in toluene resulting in a better extraction efficiency. Thus, toluene was selected for subsequent experiments. 


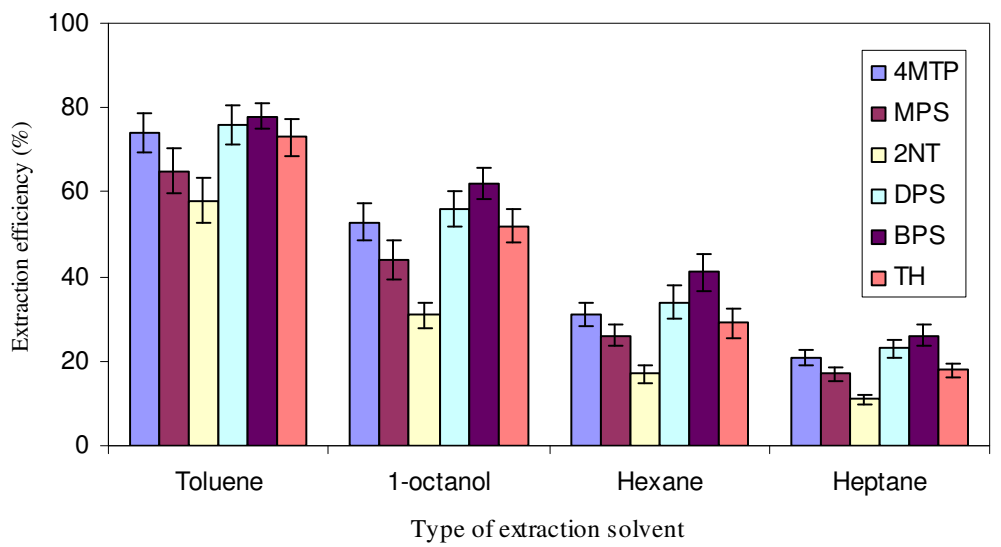

Figure 2. Effect of type of extraction solvent on the extraction efficiency.

\section{Selection of homogeneous solvent}

For HLLME-FA method, homogeneous solvent must be miscible in both water and the extraction solvent. Therefore, acetone, acetonitrile and methanol were selected for this purpose. The results showed that variation of the extraction recoveries using different homogeneous solvents was not remarkable. Therefore, acetone was selected as the homogeneous solvent because of less toxicity and low cost.

\section{Selection of extraction and homogeneous solvent volumes}

To evaluate the effect of the extraction solvent volume on the extraction efficiency, different volumes of toluene (50.0-90.0 $\mu \mathrm{L}$ at $10.0 \mu \mathrm{L}$ interval) were subjected to the same HLLME-FA procedures. As shown in the Figure 3, the preconcentration factor decreased on the increasing the volume of extraction solvent, because the volume of the collected phase was increased with the increase of toluene volume. On the basis of these results, $50.0 \mu \mathrm{L}$ of toluene was selected for the subsequent experiments.

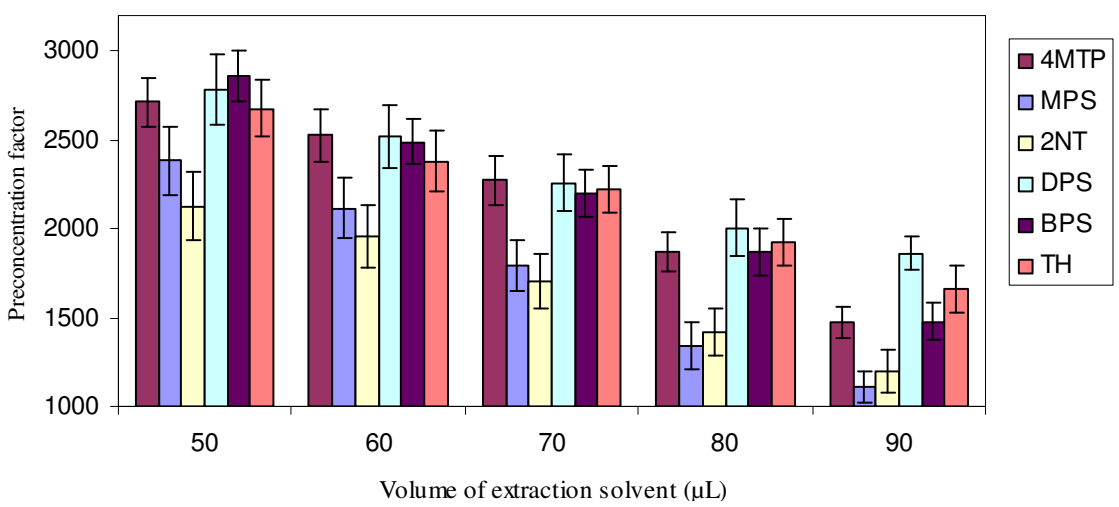

Figure 3. Effect of volume of extraction solvent on the preconcentration factor.

Bull. Chem. Soc. Ethiop. 2014, 28(2) 
In order to study the influence of the volume of the homogeneous solvent on the extraction efficiency, different volumes of acetone $(0.5,1.0,1.5$ and $2.0 \mathrm{~mL})$ were used. The results (Figure 4) showed that with an increase in the homogeneous solvent volume (acetone), the extraction efficiency decreased possibly due to an increase in the solubility of the analytes in water samples. Thus, $0.5 \mathrm{~mL}$ acetone was chosen in this work.

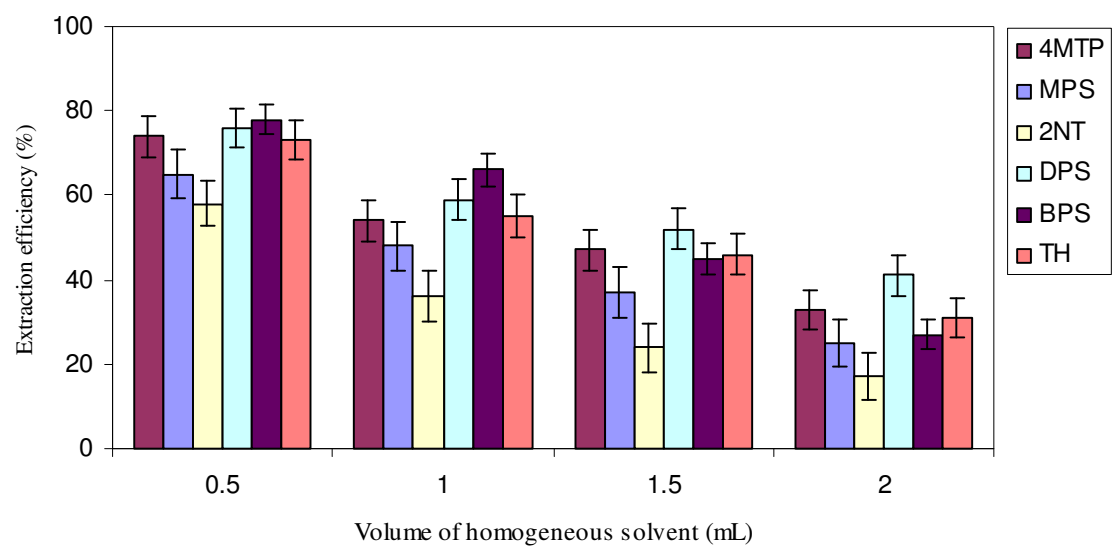

Figure 4. Effect of volume of homogeneous solvent on the extraction efficiency.

\section{Effect of salt addition}

The effect of increasing the ionic strength of the sample evaluated by adding $\mathrm{NaCl}(0.5-3 \mathrm{M})$ in to the sample solution. HLLME-FA experimental conditions were the same as those described before. Plot of extraction efficiency vs. ionic strength have been shown in Figure 5. By increasing the $\mathrm{NaCl}$ concentration up to $1.5 \mathrm{M}$, the extraction efficiency of the analytes increases, because of salting-out effect. In the higher than $1.5 \mathrm{M}$ of salt, extraction efficiency decreases, because of increase in the viscosity of solution and the resulting difficulty caused by dispersion phenomenon. Therefore, $1.5 \mathrm{M}$ of $\mathrm{NaCl}$ was selected as the optimal value for subsequent analysis.

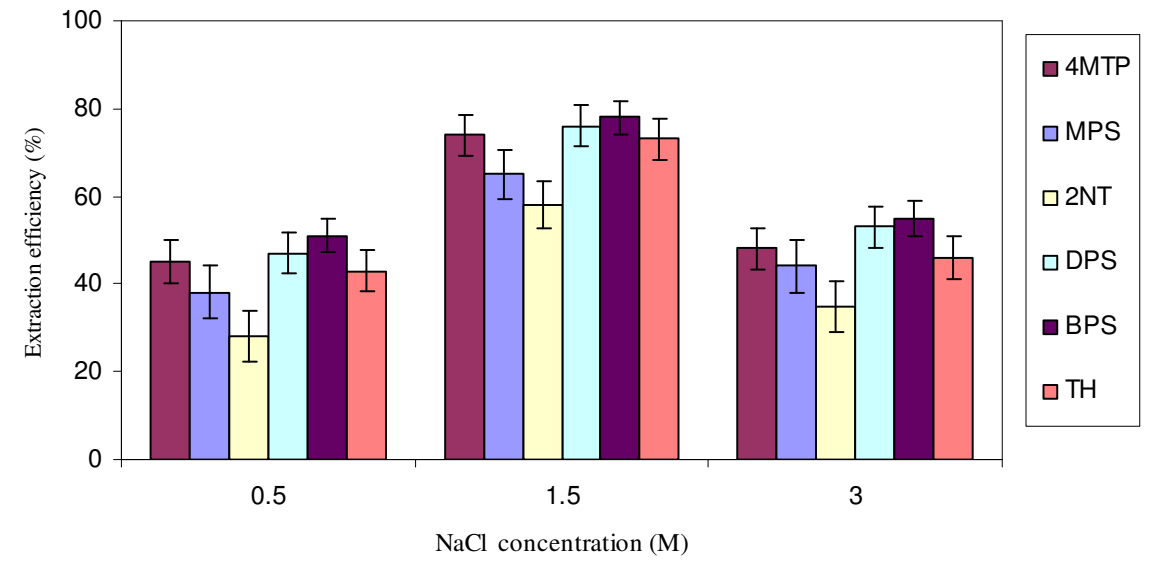

Figure 5. Effect of $\mathrm{NaCl}$ concentration on the extraction efficiency.

Bull. Chem. Soc. Ethiop. 2014, 28(2) 


\section{Effect of extraction time}

The extraction time is defined as an interval time started after dispersion and ended just before air flotation. The effect of time on the extraction efficiency was examined in the range of 1-15 min. The results show that extraction time has no significant effect on the extraction efficiency of the analytes. Because of the infinitely large contact surface area between extracting solvent and sample solution, equilibrium state was achieved rapidly in a few minutes. Hence, in the following experiments, the extraction time of $1 \mathrm{~min}$ was adopted to achieve maximal extraction efficiency of the analytes.

\section{Quantitative analysis}

The characteristics of the calibration curves given in Table 2 were obtained under optimized conditions. Linearity was observed in the range of $0.5-200 \mu \mathrm{g} \mathrm{L}^{-1}$ for $2 \mathrm{NT}$, DPS and TH, 1.0$200 \mu \mathrm{g} \mathrm{L}^{-1}$ for $4 \mathrm{MTP}, 0.25-200 \mu \mathrm{g} \mathrm{L}^{-1}$ for BPS and 2.0-200 $\mu \mathrm{g} \mathrm{L}^{-1}$ for MPS. Coefficient of determination $\left(\mathrm{r}^{2}\right)$ ranged from 0.9962 to 0.9994 . The relative standard deviations (RSDs) were calculated to be between 3.8 and $8.2 \%(\mathrm{n}=5)$. The limit of detections (LODs), based on signalto-noise $(\mathrm{S} / \mathrm{N})$ of three ranged from 0.05 to $0.4 \mu \mathrm{g} \mathrm{L}^{-1}$. Table 3 compares the proposed method with the other extraction methods for the determination of OSCs. Comparison of the proposed method with headspace solid-phase microextraction (HS-SPME) [14] and headspace sorptive extraction [17] for the extraction and determination of OSCs indicates that this novel method has a short extraction time for the determination of OSCs. Quantitative results of the proposed method such as detection limit and linear range are comparable with headspace sorptive extraction and DLLME [8] methods without using sensitive detector such as FPD and RSD of the proposed method are better than of DLLME method. Also, SPME is expensive, its fiber is fragile and has limited life-time and sample carry-over can be a problem. Also, the main advantages of the proposed method are this novel method does not need centrifugation to separate the organic phase and it is possible to the usage of low-density extraction solvents. Finally, it can be concluded that the proposed method is an efficient, rapid, simple and cheap microextraction method that can be a complement technique for DLLME and HLLE methods that have been used with organic solvents more dense than water for determination of OSCs.

Table 2. Quantitative results of HLLME-FA and GC-FID method for OSCs.

\begin{tabular}{|l|c|c|c|c|}
\hline \multirow{2}{*}{ Analyte } & \multicolumn{2}{|c|}{ Linearity } & \multirow{2}{L^{2}}{$\begin{array}{c}\text { POD } \\
\left(\mu \mathrm{g} \mathrm{L}^{-1}\right)\end{array}$} & $\begin{array}{c}\text { Precision (RSD\%, } \\
\mathrm{n}=5)^{\mathrm{b}}\end{array}$ \\
\cline { 2 - 3 } 4 MTP & $\mathrm{LDR}\left(\mu \mathrm{g} \mathrm{L}^{-1}\right)$ & $\mathrm{R}^{2 \mathrm{c}}$ & 0.2 & 4.5 \\
\hline MPS & $1.0-200$ & 0.9993 & 0.4 & 7.8 \\
\hline 2NT & $2.0-200$ & 0.9962 & 0.1 & 8.2 \\
\hline DPS & $0.5-200$ & 0.9994 & 0.1 & 6.1 \\
\hline BPS & $0.5-200$ & 0.9976 & 0.1 & 3.8 \\
\hline TH & $0.25-200$ & 0.9989 & 0.05 & 5.4 \\
\hline
\end{tabular}

${ }^{\mathrm{a}} \mathrm{LOD}$, limit of detection for $\mathrm{S} / \mathrm{N}=3$; ${ }^{\mathrm{b}} \mathrm{RSD}$, relative standard deviation $(\mathrm{n}=5)$; ${ }^{\mathrm{c}}$ coefficient of determination. 
Table 3. Comparison of the proposed method with other extraction methods for the determination of the organosulfur compounds.

\begin{tabular}{|c|c|c|c|c|c|}
\hline Methods & R.S.D.\% & $\begin{array}{c}\text { Dynamic linear } \\
\text { range }\left(\mu \mathrm{g} \mathrm{L}^{-1}\right)\end{array}$ & $\begin{array}{c}\text { Limit of detection } \\
\left(\mu \mathrm{g} \mathrm{L}^{-1}\right)\end{array}$ & $\begin{array}{c}\text { Extraction } \\
\text { time }(\mathrm{min})\end{array}$ & $\begin{array}{c}\text { Ref. } \\
\text { HS-SPME-GC-FPD* }\end{array}$ \\
\hline HS-SE-GC-FPD* & $4.5-10.2$ & $0.1-1000$ & $0.01-0.05$ & 20 & {$[14]$} \\
\hline DLLE-GC-FPD* & $8.5-13.7$ & $0.8-850$ & $0.21-3.05$ & $20 \mathrm{~s}$ & {$[8]$} \\
\hline HLLME-FA-GC-FID* & $3.8-8.2$ & $0.5-200$ & $0.05-0.4$ & 1 & This work \\
\hline
\end{tabular}

HSP-SPME - Headspace solid-phase microextraction; HSP-SE - Headspace sorptive extraction; DLLE Dispersive liquid-liquid microextraction.

\section{Real water analysis}

The proposed HLLME-FA-GC procedure described above was applied to the determine OSCs concentration in river (the water was collected from Langrud River (Gilan, Iran)), tap (the water was collected from our laboratory (Tehran, Iran) and well water (the water was collected from the well in Tehran) samples. The results of tap, river and well water samples showed that they were free of OSCs contamination. Figure 6 shows the chromatograms obtained for river water and spiked river water. To determine the effect of matrices on the extraction procedures, the relative recoveries of the samples spiked with the known amounts of the analytes were investigated. The results obtained are summarized in Table 4 . The relative recoveries vary from 80 to $98 \%$, indicating the feasibility of the HLLME-FA method for the determining of the target analytes in the water samples.

Table 4. Determination of OSCs in tap, river and well water samples and relative recovery of spiked OSCs in them.

\begin{tabular}{|c|c|c|c|c|c|c|c|}
\hline \multicolumn{2}{|l|}{ Sample } & 4 MTP & MPS & $2 \mathrm{NT}$ & DPS & BPS & $\mathrm{TH}$ \\
\hline \multirow{4}{*}{$\begin{array}{l}\text { Well }^{\mathrm{b}} \\
\text { water }\end{array}$} & Initial concentration $^{\mathrm{a}}$ & - & - & - & - & - & - \\
\hline & Found $^{\mathrm{c}}$ & 4.4 & 4.1 & 4.5 & 4.6 & 4.7 & 4.8 \\
\hline & Relative recovery (\%) & 88 & 82 & 90 & 92 & 94 & 96 \\
\hline & RSD $\%$ & 6.3 & 9.7 & 10.2 & 8.7 & 5.8 & 7.8 \\
\hline \multirow[t]{4}{*}{ Tap $^{\mathrm{d}}$ water } & Initial concentration & - & - & - & - & - & - \\
\hline & Found & 1.8 & 1.7 & 1.9 & 1.7 & 1.8 & 1.6 \\
\hline & Relative recovery (\%) & 90 & 85 & 95 & 85 & 90 & 80 \\
\hline & RSD \% & 5.1 & 8.2 & 9.3 & 7.6 & 4.7 & 6.1 \\
\hline \multirow[t]{4}{*}{ River $^{\mathrm{b}}$ water } & Initial concentration & - & - & - & - & - & - \\
\hline & Found & 4.3 & 4.1 & 4.5 & 4.6 & 4.4 & 4.9 \\
\hline & Relative recovery (\%) & 86 & 82 & 90 & 92 & 88 & 98 \\
\hline & RSD \% & 7.4 & 10.3 & 11.6 & 9.3 & 7.1 & 8.9 \\
\hline
\end{tabular}

${ }^{\mathrm{a}}$ All concentrations are in $\mu \mathrm{g} \mathrm{L}{ }^{-1}$. ${ }^{\mathrm{b}} 5.0 \mu \mathrm{g} \mathrm{L}{ }^{-1}$ of each OSC was added. ${ }^{\mathrm{c}}$ Concentration of OSC spiked samples that found by proposed HLLME-FA method. ${ }^{\mathrm{d}} 2.0 \mu \mathrm{g} \mathrm{L}^{-1}$ of each OSC was added. 


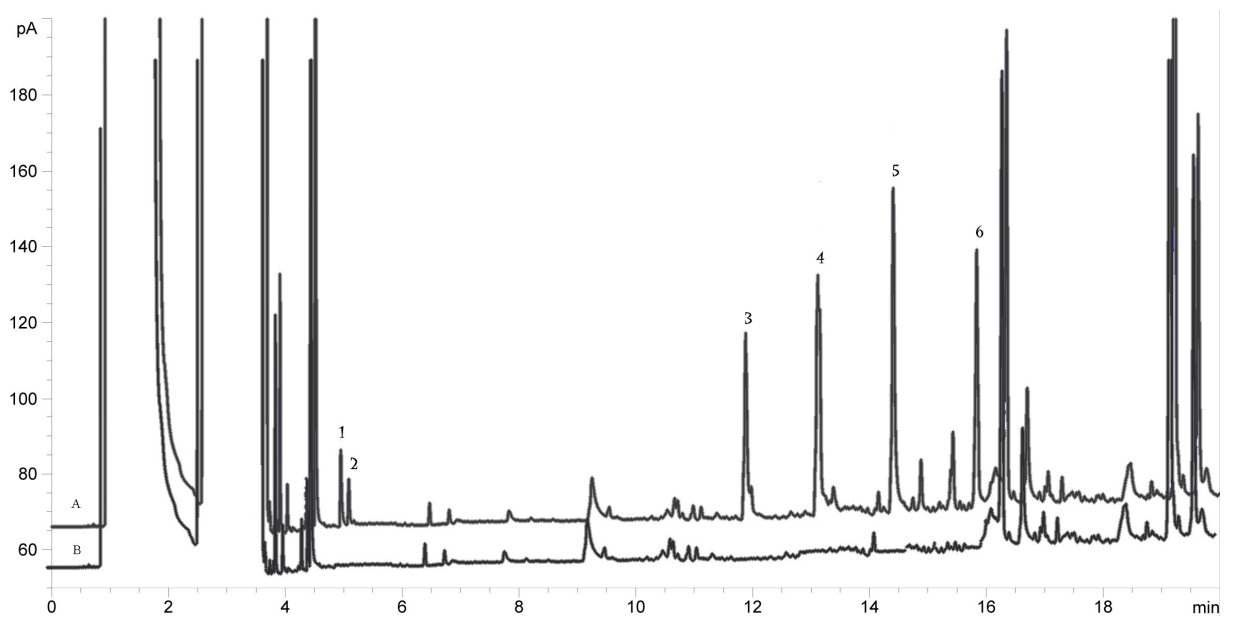

Figure 6. GC-FID chromatograms of analytes in river water, before spiking (B) and after spiking with $5.0 \mu \mathrm{g} \mathrm{L}^{-1}$ of each OSCs (A) using proposed method combined with GC-FID under optimum conditions (1: 4 MTP, 2: MPS, 3: 2 NT, 4: DPS, 5: BPS, 6: TH).

\section{CONCLUSION}

This paper describes a HLLME-FA method combined with GC-FID that is applied to the analysis of 6 organic sulfur compounds in environmental water samples. The results of this study demonstrate that the proposed methods give acceptable relative recoveries and repeatability for the OSCs from tap, river and well water samples. The proposed method is linear over a wide range and detection limits at $\mu \mathrm{g} \mathrm{L}^{-1}$ level were achieved. In this method sample preparation time as well as consumption of organic solvents was minimized without affecting the sensitivity of the method. The developed method was convenient for the usage of low-density extraction solvents. No centrifugation was required in this method. Air flotation was used to breakup organic solvent in water emulsion and to finish the extraction process.

\section{ACKNOWLEDGEMENTS}

Financial support from Yadegar - e-Imam Khomeini (RAH) Branch, Islamic Azad University, Tehran, Iran for the support during the period of this research is gratefully acknowledged.

\section{REFERENCES}

1. Wolska, L.; Namiesnik, J. Pol. J. Environ. Stud. 2002, 11, 655.

2. Ras, M.R.; Borrull, F.; Marce, R.M. Talanta 2008, 74, 562.

3. Lestremau, F.; Andersson, F.A.T.; Desauziers, V.; Fanlo, J.L. Anal. Chem. 2003, 75, 6226.

4. Nielsen, A.T.; Jonsson, S. J. Chromatogr. A 2002, 963, 57.

5. Smet, E.; Van Langenhove, H. Biodegradation 1998, 9, 273.

6. Li, K.C.; Shooter, D. Int. J. Environ. Anal. Chem. 2004, 84, 749. 
7. Vassilakos, C.; Papadopoulos, A.; Lahaniat, M.; Maggos, T.; Bartzis, J.; Papagianakopoulos, P. Fresenius Environ. Bull. 2002, 11, 516.

8. Xiong, J.; Hu, B. J. Chromatogr. A 2008, 1193, 7.

9. Berube, P.R.; Parkinson, P.D.; Hall, E.R. J. Chromatogr. A 1999, 830, 485.

10. Wong, J.W.; Webster, M.G.; Halverson, C.A.; Hengel, M.J.; Ngim, K.K.; Ebeler, S.E. J. Agric. Food Chem. 2003, 51, 1148.

11. Wang, Y.; Kwok, Y.C.; He, Y.; Lee, H.K.; Anal. Chem. 1998, 70, 4610.

12. Link, D.D.; Baltrus, J.P.; Rothenberger, K.S. Energy Fuel 2003, 17, 1292.

13. Lavigne-Delcroin, A.; Tusseau, D.; Proix, M. Sci. Aliment. 1996, 16, 267.

14. Hill, P.G.; Smith, R.M. J. Chromatogr. A 2000, 872, 203.

15. Mestres, M.; Busto, O.; Guasch, J. J. Chromatogr. A 2002, 945, 211.

16. Darriet, P.; Tominaga, T.; Lavigne, V.; Boidron, J.N.; Dubourdieu, D. Flavour Fragr. J. 1995, 10, 385.

17. Yu, C.; Li, X.; Hu, B. J. Chromatogr. A 2008, 102, 1202.

18. Farajzadeh, M.A.; Seyedi, S.E.; Shalamzari, M.S.; Bamorowat, M. J. Sep. Sci. 2009, 32, 3191.

19. Saleh, A.; Yamini, Y.; Faraji, M.; Rezaee, M.; Ghambarian, M. J. Chromatogr. A 2009, $1216,6673$.

20. Leong, M.; Huang, S.D. J. Chromatogr. A 2008, 1211, 8.

21. Zhou, Q.X.; Bai, H.H.; Xie, G.H.; Xiao, J.P. J. Chromatogr. A 2008, 1188, 148.

22. Kocurova, L.; Balogh, I.S.; Sandrejova, J.; Andruch, V. Microchem. J. 2012, 102, 11.

23. Hashemi, P.; Beyranvand, S.; Siah Mansur, R.; Ghiasvand, A.R. Anal. Chim. Acta 2009, 655,60 .

24. Farajzadeh, M.A.; Djozan, Dj.; Fazeli Bakhtiyari, R. Talanta 2010, 81,1360.

25. Rodriguez-Cabo, T.; Rodriguez, I.; Ramil, M.; Cela, R. J. Chromatogr. A 2011, 1218, 6603.

26. Ghambari, H.; Hadjmohammadi, M.R. J. Chromatogr. B 2012, 899, 66.

27. Guo, L.; Lee, H.K. J. Chromatogr. A 2011, 1218, 5040.

28. Mashkouri Najafi, N.; Tavakoli, H.; Abdollahzadeh, Y.; Alizadeh, R. Anal. Chim. Acta 2012, 714, 82 .

29. Chen, H.; Chen, R.W.; Li, S.Q. J Chromatogr. A 2010, 1217, 1244.

30. Leong, M.I.; Huang, S.D. J. Chromatogr. A 2008, 1211, 8.

31. Haji Hosseini, M.; Rezaee, M.; Mashayekhi, H.A.; Akbarian, S.; Mizani, F.; Pourjavid, M.R. J. Chromatogr. A 2012, 1265, 52. 